\title{
Development of a model for the analysis of wheel wear in railway vehicles
}

\section{J. Auciello, M. Ignesti, L. Marini, E. Meli \& A. Rindi}

\section{Meccanica}

An International Journal of Theoretical and Applied Mechanics AIMETA

ISSN 0025-6455

Volume 48

Number 3

Meccanica (2013) 48:681-697

DOI 10.1007/s11012-012-9624-4

\section{Meccanica}

An International Journal of Theoretical and Applied Mechanics

AIMETA

\section{黛 Springer}


Your article is protected by copyright and all rights are held exclusively by Springer Science +Business Media Dordrecht. This e-offprint is for personal use only and shall not be selfarchived in electronic repositories. If you wish to self-archive your work, please use the accepted author's version for posting to your own website or your institution's repository. You may further deposit the accepted author's version on a funder's repository at a funder's request, provided it is not made publicly available until 12 months after publication. 


\title{
Development of a model for the analysis of wheel wear in railway vehicles
}

\author{
J. Auciello • M. Ignesti • L. Marini · E. Meli • \\ A. Rindi
}

Received: 5 April 2012 / Accepted: 5 October 2012 / Published online: 19 October 2012

(C) Springer Science+Business Media Dordrecht 2012

\begin{abstract}
In railway applications, the estimation of the wear at the wheel-rail contact is an important field of study, mainly correlated to the planning of maintenance interventions, vehicle stability and the possibility to carry out specific strategies for the wheel profile optimization.

In this work Authors present a model conceived for the evaluation of the wheel profile evolution due to wear, which is organized in two parts, mutually interactive: a vehicle model for the dynamic analysis and a model for the wear estimation.

The wheel wear evolution is reproduced by dividing the overall chosen mileage to be simulated in discrete spatial steps: at each step the dynamic simulations are performed by means of the vehicle model keeping the wheel profile constant, while the wheel geometry is updated through the wear model only at the end of the discrete step. Thus, the two parts of the
\end{abstract}

\author{
J. Auciello · M. Ignesti · L. Marini · E. Meli $(\varangle) \cdot$ A. Rindi \\ Department of Energy Engineering, University of \\ Florence, Florence, Italy \\ e-mail: meli@mapp1.de.unifi.it \\ J. Auciello \\ e-mail: auciello@mapp1.de.unifi.it \\ M. Ignesti \\ e-mail: ignesti@mapp1.de.unifi.it \\ L. Marini \\ e-mail: marini@mapp1.de.unifi.it
}

A. Rindi

e-mail: rindi@mapp1.de.unifi.it whole model work alternately until the completion of the whole established mileage. Clearly, the choice of an appropriate step length is one of the most important aspect of the procedure and it affects directly the result accuracy and the required computational time to complete the analysis.

The entire model has been validated in collaboration with Trenitalia S.p.A and RFI, which has provided the technical documentation and the experimental results relating to some tests performed on a scenery that exhibits serious problems in terms of wear represented by the vehicle ALn 501 "Minuetto" on the Aosta-Pre Saint Didier line.

Keywords Multibody modeling - Railway vehicles . Wheel-rail contact . Wheel-rail wear

\section{Introduction}

The wear at the wheel-rail interface is an important problem in railway field. The evolution of the profile shape due to wear has a deep effect on the vehicle dynamics and on its running stability, leading to performance variations both in negotiating curves and in straight track. Therefore the original profiles have to be periodically re-established by means of turning. The correct prediction of the wear rate in a particular context may be very important in the planning of the wheelset maintenance interventions. These fundamental operations which are periodically necessary, 
are quite onerous both in economic sense and in terms of vehicle's availability; hence it is certainly advantageous to reduce their frequency.

As a further application, a reliable wear model can also be used in the optimization of the wheel profile from the wear point of view. The research of an optimal shape of the wheel for a particular railway application may be useful to guarantee an uniform wear, which implies almost stable characteristics of the contact geometry. In this way, not only the wear rate may be reduced leading to an higher mean time between two maintenance interventions, but the performance of the wheel-rail contact may be kept nearly constant in the time.

In this work authors will present a complete model to predict the evolution of wheel profiles due to wear that involves multibody simulations and a wear model. More precisely, the general layout adopted is made up of two parts mutually interactive: the vehicle model (multibody model and wheel-rail global contact model) and a wear model (local contact model, wear evaluation using an experimental law and wheel profile update). The multibody model is implemented with the commercial multibody code SIMPACK: the accurate three-dimensional dynamic modeling of the vehicle's motion takes into account all the significant degrees of freedom and nonlinearities. Starting from the kinematic variables evaluated by the multibody model (wheelset position and orientation and their derivatives) the global contact model, developed by authors in previous works [14-16], calculates the contact forces between wheelset and rail and interacts online with the multibody model without lookup-table, to reproduce the vehicle dynamics; in particular, it uses an innovative algorithm for the detection of the contact points between wheelset and rail, with a fully 3D semi-analytical approach to the problem. As regards the wear part (implemented in the MATLAB ${ }^{\circledR}$ environment), the local contact model exploits the outputs of the multibody simulations (contact points, contact forces, global creepages) to calculate the contact pressures and the local slip inside the contact area while, thanks to the knowledge of these quantities, the wear model evaluates the amount of removed material and its distribution along the wheel profile; the removal of material and the profile update are carried out considering the fully $3 \mathrm{D}$ structure of the phenomenon.

In the development of an accurate wear model [2, $7,18,22]$, one of the most critical aspect is the avail- ability of experimental results, since the collection of the data requires at least a few months with relevant economic costs. In the study case the entire model has been validated thanks to the technical and experimental data related to the Aln 501 "Minuetto" vehicle and the measured wear progress provided by Trenitalia S.p.A. as well as the track data given by Rete Ferroviaria Italiana (RFI) and relative to the statistical analysis of Aosta-Pre Saint Didier railway line. This is a very sharp track on the Italian Railways and the scenery is rather interesting since the Aln 501 "Minuetto" exhibits serious problems on this track in terms of wear, requiring frequent maintenance interventions on the wheels.

The main advantages of the wear model proposed in this paper (compared to other wear models with analogous architecture and similar requirements in terms of accuracy and numerical efficiency) can be summarized as follows:

- the employment in the dynamical simulations of new global contact models based on semi-analytical methods $[14,15]$ rather than on classical rigid formulations or on formulations based on approximated discretized look-up tables (LUT) (see by example [1, 19]) allows the achievement both of an high numerical efficiency (and consequently the direct implementability within multibody codes without discretized LUT) and of an high accuracy level;

- the employment of local wear models based on local contact models (see [12] and [3]) instead of less accurate global wear models based on global contact models (as, by example, in many important multibody codes like SIMPACK [13, 21]) leads to an improvement in terms of accuracy (possible thanks to the numerical efficiency of the new global contact models used in the numerical simulations);

- the validation of the wear model trough experimental data directly measured online on the railway track (thanks to the cooperation with Trenitalia and Rete Ferroviaria Italiana) rather than other software tools or experimental data obtained from proofs performed on scaled test rigs (see [2, 7, 17, 18, 22]) assures a better standard of accuracy;

- the chance of employing different update strategies for the wheel profile depending on the characteristics of the considered problems (see [11, 24]). 


\section{General architecture of the model}

The general layout of the model has been arranged in agreement with Trenitalia S.p.A and RFI, according to the following main working hypotheses:

- discrete approach to the wear evolution, dividing the entire distance to be simulated in steps and updating the wheel profile after each step;

- the wheel profile used in the dynamic simulations is the same for each vehicle's wheel and the output of the wear model is the evolution of a single mean wheel profile;

- the track is not subjected to wear and the rail profiles keep their initial profiles (a statistically representative worn profile provided by RFI has been considered for each class of curves of the statistical analysis as will be explained in detail in the following);

- acceleration and braking phases are not taken into account;

- the wheel-rail contact is hypothesized under dry conditions.

The numerical evolution of the wheels shape is treated with a discrete approach. The entire mileage to be simulated is divided in a few spatial steps, in which the wheel profile is maintained constant during the dynamical simulations; the results of the wear evaluation, at the end of the current step, allow the update of the wheel profile for the next step of the procedure. The step length depends on the total distance to be covered and it is one of the most important aspect of the entire numerical procedure, because it directly affects the model precision: in fact, the smaller is the step, the higher the accuracy and the overall computation time are; hence the choice has to be a compromise between these aspects.

Moreover, from a numerical point of view, the step length can be chosen either constant during the overall distance or variable (introducing for example a threshold on the maximum of removed material); nevertheless, since the wear progress is almost linear with respect to the traveled distance, the constant step length turns out to be a quite suitable choice for this kind of problem, providing comparable results in terms of accuracy and better performance in terms of numerical efficiency.

Since the wheel wear in railway applications is a phenomenon which requires at least tens of thousand kilometers (but even hundreds of thousands in the most cases) to express its effects, the simulated distances cannot be as long as the real ones to be investigated, because they would require unacceptable computational times, even if the whole track has been divided into discrete steps. As will be explained in following this issue can be overcome hypothesizing within the discrete step a proportionality between the wear relative to the single discrete step and the amount of wear relative to the distance really simulated by means of the numerical multibody model (that is the two wear rates are the same); this hypothesis is reasonable only if the numerically simulated track is a significant representation, in statistical terms, of the track associated to the discrete spatial step.

A diagram representation of the whole model is visible in Fig. 1: it includes two main parts that work alternatively during each step. On the left there is the vehicle model, the part which is responsible for the dynamic simulations, made up of the multibody model and the global contact model developed by authors in previous work [14, 15]; the two subsystems interact online to each other without lookup-table during the simulations to reproduce the vehicle dynamics. On the right there is the wear evaluation, which comprises three sub-parts: the local contact model, the wear model and the wheel profile update. In more detail, during the dynamical simulations in the first task of each procedure step, the multibody model implemented in SIMPACK exchanges data continuously at each time step with the global contact model, passing the wheelset kinematic variables (wheelset position and orientation and their derivatives) and receiving the global contact variables (positions of the contact points $\mathbf{P}_{c}^{r}$, the wheel-rail contact forces $N, T_{x}$, $T_{y}$ and the global creepages $\left.\xi_{x}, \xi_{y}, \xi_{s p}\right)$. Once the multibody simulations are completed, the local contact model (written in MATLAB and based on the FASTSIM algorithm [12]) evaluates, starting from the global contact variables, the contact pressures and the local slip $\left(\mathbf{p}_{t}, p_{n}, \mathbf{s}\right)$ inside each detected contact patch; the removed material and its distribution along the wheel profile are then obtained passing these data to the wear model, by means of an experimental relationship between the removed material by wear and the energy dissipated by friction at the contact interface [2, 7, 22]. Finally, the wheel profile is updated through suitable numerical procedures.

From the track viewpoint the evolution of the wheel wear can be approached in different manners, depending on the goals of the study. If the aim is the analysis 


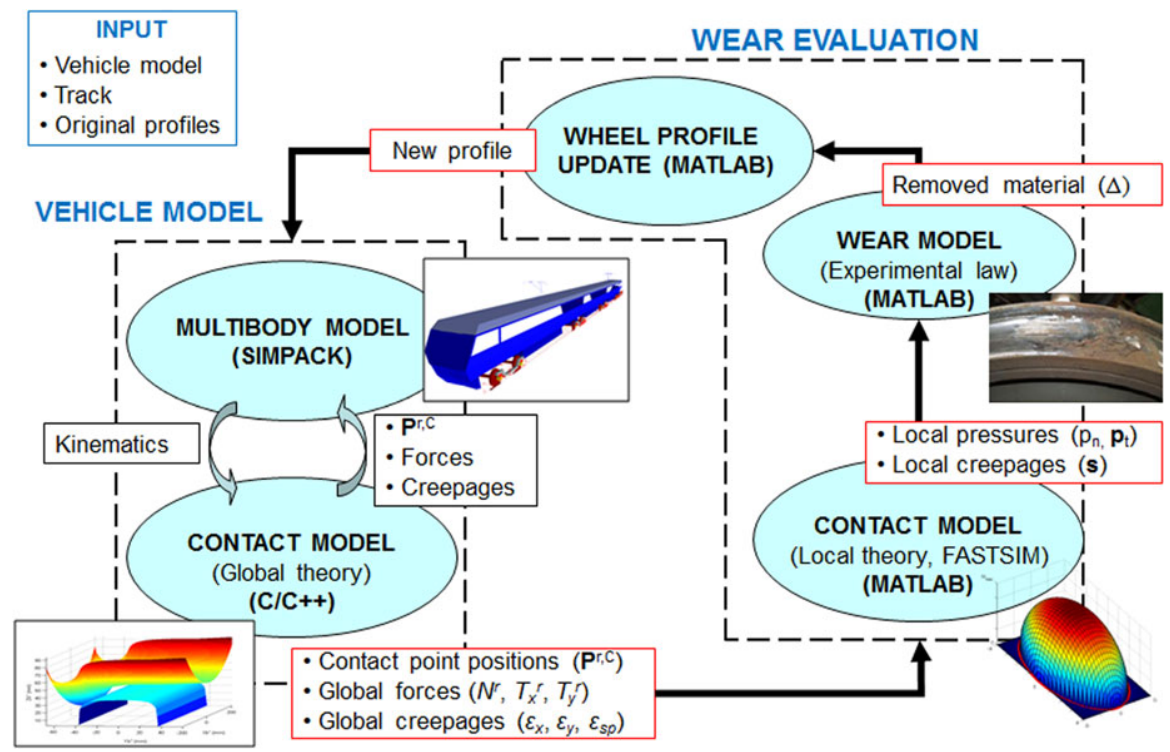

Fig. 1 General architecture of the model

of the phenomenon on a long track or on a complex railway line with many vehicles in service, a statistical approach is necessary to achieve general significant results in a reasonable time. In this work, the entire considered railway track (the Aosta-Pre Sain Didier line) has been substituted with an equivalent set of different curved tracks, classified by radius, superelevation and traveling speed, which has been built consulting a detailed track database provided by Rete Ferroviaria Italiana as will be explained in details in the following.

\section{The vehicle model}

\subsection{The multibody model}

The railway vehicle on which this study has been performed is the ALn 501 Minuetto (Fig. 2). It is made up of three coaches and four bogies with two wheelsets; the external bogies are motorized whereas the two intermediate trailer bogies are of Jacobs type, shared between two coaches (Fig. 3).

As in the most part of passenger trains, the bogies are provided with two stages of suspensions. The primary suspensions, which link the axleboxes with the bogie frame, are constituted by Flexicoil springs, made up of two coaxial springs, which mainly provide the vertical stiffness in this stage. A non linear damper

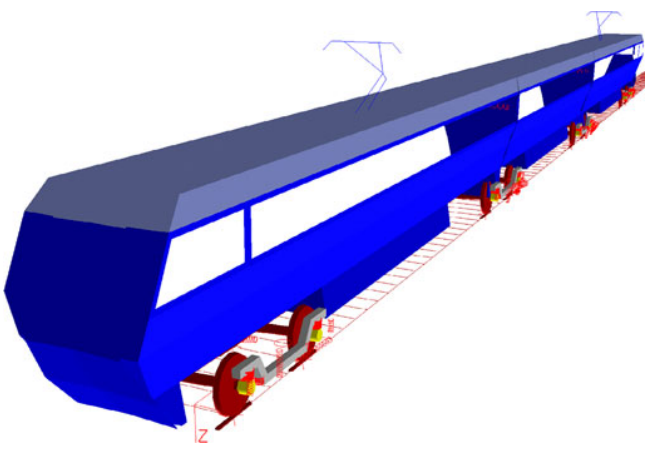

Fig. 2 The Aln 501 Minuetto multibody model

is responsible for the damping of the vertical relative displacements. The secondary suspension stage comprises two airsprings (four in the Jacobs bogie) for the vertical, longitudinal and lateral stiffness (used to guarantee passengers comfort and a simple automatic regulation of the coaches height with changes in the vertical loads), a non linear longitudinal rod (to transmit the traction and braking efforts), a torsion bar (to provide the correct rolling stiffness), non linear lateral bumpstops and non linear dampers (lateral, vertical and anti-yaw). All the described devices have been modeled as viscoelastic force elements, taking into account all the mechanical non linearities [5, 10]. The resultant whole SIMPACK multibody model includes 31 rigid bodies: 3 coaches, 4 bogie frames, 


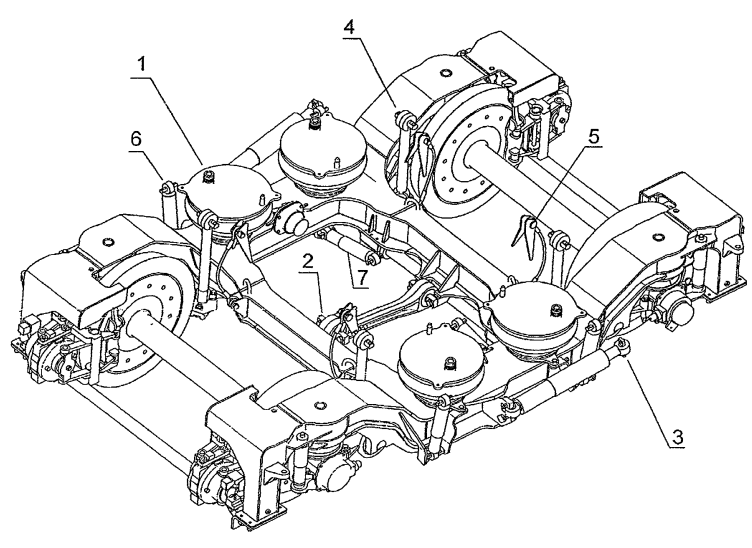

Fig. 3 The Jacobs bogie

Table 1 The Aln 501 Minuetto main inertial properties

\begin{tabular}{lrrrr}
\hline & $\begin{array}{l}\text { Mass } \\
\mathrm{kg}\end{array}$ & \multicolumn{1}{l}{$\begin{array}{l}I_{x x} \\
\mathrm{~kg} \mathrm{~m}^{2}\end{array}$} & \multicolumn{1}{c}{$\begin{array}{l}I_{y y} \\
\mathrm{~kg} \mathrm{~m}^{2}\end{array}$} & \multicolumn{1}{c}{$\begin{array}{l}\mathrm{k}_{z z} \\
\mathrm{~kg} \mathrm{~m}^{2}\end{array}$} \\
\hline External coach & 31568 & 66700 & 76400 & 743000 \\
Internal coach & 14496 & 30600 & 245000 & 236000 \\
Motor bogie frame & 3306 & 1578 & 2772 & 4200 \\
Trailer bogie frame & 3122 & 1647 & 3453 & 5011 \\
Wheelset & 2091 & 1073 & 120 & 1073 \\
\hline
\end{tabular}

Table 2 Main linear stiffness properties of the ALn 501 Minuetto

\begin{tabular}{lll}
\hline Primary suspension & Flexicoil $k_{z}$ & $9.01 \mathrm{E}+05 \mathrm{~N} / \mathrm{m}$ \\
& Flexicoil $k_{x}, k_{y}$ & $1.26 \mathrm{E}+06 \mathrm{~N} / \mathrm{m}$ \\
& Sutuco $k_{x}$ & $2.0 \mathrm{E}+07 \mathrm{~N} / \mathrm{m}$ \\
& Sutuco $k_{y}$ & $1.5 \mathrm{E}+07 \mathrm{~N} / \mathrm{m}$ \\
Secondary suspension & Airspring $k_{z}$ & $3.98 \mathrm{E}+05 \mathrm{~N} / \mathrm{m}$ \\
& Airspring $k_{x}, k_{y}$ & $1.2 \mathrm{E}+05 \mathrm{~N} / \mathrm{m}$ \\
& Anti-roll bar $k_{\alpha}$ & $2.6 \mathrm{E}+06 \mathrm{Nm} / \mathrm{rad}$ \\
& & \\
Coach connection & Bushing $k_{x}, k_{z}$ & $7.24 \mathrm{E}+07 \mathrm{~N} / \mathrm{m}$ \\
& Bushing $k_{y}$ & $5.2 \mathrm{E}+06 \mathrm{~N} / \mathrm{m}$ \\
\hline
\end{tabular}

8 wheelsets and 16 axleboxes. The most significant inertial properties of the model bodies are summarized in Table 1; moreover the main linear characteristics of the suspensions are summarized in Table 2.

\subsection{The global contact model}

The global contact model allows the online calculation of the contact forces at the wheel-rail interface during the multibody simulations. The model is based on a semianalytic approach that guarantees the following features (see also $[19,20]$ ):

- generic wheel and rail profiles can be implemented;

- fully 3D handling of the problem, with all degrees of freedom between wheel and rail taken into account;

- no simplifying hypotheses on the problem geometry and kinematics;

- multiple points of contact are allowed with no bounds to the their overall number;

- high numerical efficiency which allows the online implementation directly within the multibody models, without look-up tables; numerical performance better than those obtainable with commercial softwares (Vi-Rail ${ }^{\mathrm{TM}}$, SIMPACK) [14-16].

The contact model consists of two sequential phases: the research of the contact points and the computation of the normal and tangential actions in each contact patch. The first task is entrusted to an algorithm developed by authors in previous works (the DIST method $[9,14,15])$ that takes into account the original multi-dimensional contact problem and reduces it to a simpler scalar problem, which can be easily handled by means of numerical methods, with remarkable advantages:

- the multiple solution management is simpler;

- a wide range of algorithms, even the elementary non-iterative ones, can efficiently resolve the numerical problem;

- the convergence of the iterative algorithms can be easily achieved and the algorithm converges to the solutions with fewer iterations and less computational effort.

The algorithm for the detection of contact points is based on the standard idea that the distance between the wheel surface and the rail surface is stationary in the considered points $[4,9,14-16]$.

Two reference systems are introduced to formulate the problem: the auxiliary system $O_{r} x_{r} y_{r} z_{r}$ and the local system $O_{w} x_{w} y_{w} z_{w}$. The first system moves along the track centerline following the wheelset: the $x_{r}$ is tangent to the centerline in the $O_{r}$ point while the $z_{r}$ axis is perpendicular to the plane of track; the position of $O_{r}$ can be determined imposing that the $y_{r} z_{r}$ plane contains the wheelset centre of mass $G_{w}$. The local system is fixed on the wheelset, except for the rotation around the wheelset axle: in particular, $O_{w} \equiv G_{w}, y_{w}$ 


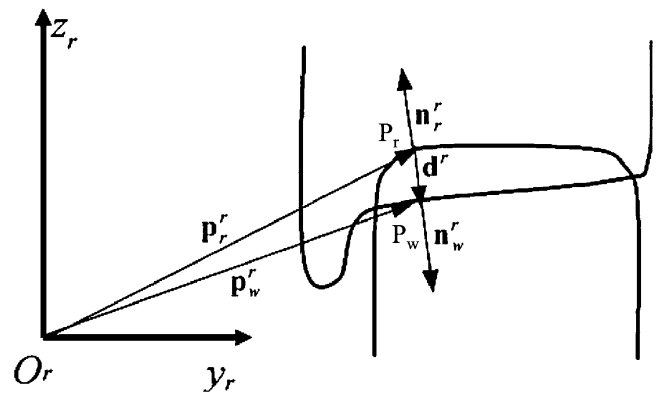

Fig. 4 The distance method

coincides with the wheelset rotation axis and $x_{w}$ is in the $x_{r} y_{r}$ plane. In the following $\mathbf{p}_{w}^{r}$ and $\mathbf{p}_{w}^{w}$ will be the positions of a point on the wheel surface in the auxiliary system and in the local system respectively, while the position of a point on the rail surface in the auxiliary system will be indicated with $\mathbf{p}_{r}^{r}$. At this point, the geometrical conditions can be stated as follows (Fig. 4):

- the normal unitary vector relative to the rail surface $\mathbf{n}_{r}^{r}\left(\mathbf{p}_{r}^{r}\right)$ and the wheel surface unitary vector $\mathbf{n}_{w}^{r}\left(\mathbf{p}_{w}^{r}\right)$ have to be parallel ( $\mathbf{R}_{2}$ is the rotation matrix that links the local system to the auxiliary one):

$\mathbf{n}_{r}^{r}\left(\mathbf{p}_{r}^{r}\right) \times \mathbf{n}_{w}^{r}\left(\mathbf{p}_{w}^{r}\right)=\mathbf{n}_{r}^{r}\left(\mathbf{p}_{r}^{r}\right) \times \mathbf{R}_{2} \mathbf{n}_{w}^{w}\left(\mathbf{p}_{w}^{w}\right)=\mathbf{0} ;$

the wheel and rail surfaces can be locally considered as a revolution and an extrusion surface respectively: $\mathbf{p}_{w}^{w T}=\left(x_{w}, y_{w},-\sqrt{w\left(y_{w}\right)^{2}-x_{w}^{2}}\right)$, $\mathbf{p}_{r}^{r T}=\left(x_{r}, y_{r}, r\left(y_{r}\right)\right)$, where the generative function $w\left(y_{w}\right)$ and $r\left(y_{r}\right)$ are supposed to be known;

- the rail surface normal unitary vector $\mathbf{n}_{r}^{r}\left(\mathbf{p}_{r}^{r}\right)$ and the distance vector $\mathbf{d}^{r}=\mathbf{p}_{w}^{r}-\mathbf{p}_{r}^{r}$ between the generic point of the wheel and of the rail have to be parallel:

$$
\mathbf{n}_{r}^{r}\left(\mathbf{p}_{r}^{r}\right) \times \mathbf{d}^{r}=\mathbf{0} .
$$

The distance between the generic points on the wheel and on the rail can be expressed as

$$
\begin{aligned}
\mathbf{d}^{r}\left(x_{w}, y_{w}, x_{r}, y_{r}\right)= & \mathbf{p}_{w}^{r}\left(x_{w}, y_{w}\right)-\mathbf{p}_{r}^{r}\left(x_{r}, y_{r}\right) \\
= & \mathbf{o}_{w}^{r}+\mathbf{R}_{2} \mathbf{p}_{w}^{w}\left(x_{w}, y_{w}\right) \\
& -\mathbf{p}_{r}^{r}\left(x_{r}, y_{r}\right)
\end{aligned}
$$

thus, $\mathbf{d}^{r}$ depends on the four parameters $\left(x_{w}, y_{w}\right.$, $\left.x_{r}, y_{r}\right)$ identifying the generic points $\mathbf{p}_{w}^{w}\left(x_{w}, y_{w}\right)$ and $\mathbf{p}_{r}^{r}\left(x_{r}, y_{r}\right)$ on the contact surfaces. Equations (1) and (2) constitute a system of six scalar equations and four unknowns $\left(x_{w}, y_{w}, x_{r}, y_{r}\right)$ (only four of the equations are independent). As previously stated, the original 4D problem can be reduced to a scalar equation in the unknown $y_{w}$ expressing $x_{w}, x_{r}$, and $y_{r}$ as functions of $y_{w}$. By means of suitable analytical procedures, from the second component of (1) the expression $x_{w 1,2}\left(y_{w}\right)$ (two possible values are present for each $y_{w}$ ) can be obtained; then, similarly, from the first component of (1) the expression for $y_{r 1,2}\left(y_{w}\right)$ can be determined and from the second component of (2) the relation $x_{r 1,2}\left(y_{w}\right)$. Finally, replacing the variables $x_{w 1,2}\left(y_{w}\right), x_{r 1,2}\left(y_{w}\right)$ and $y_{r 1,2}\left(y_{w}\right)$ in the first component of (2), two simple scalar equations in the $y_{w}$ variable can be found:

$$
\begin{aligned}
F_{1,2}\left(y_{w}\right)= & -r^{\prime}\left(y_{r 1,2}\left(y_{w}\right)\right)\left(G_{z}+r_{32} y_{w}\right. \\
& -r_{33} \sqrt{w\left(y_{w}\right)^{2}-x_{w 1,2}\left(y_{w}\right)^{2}} \\
& \left.-r\left(y_{r 1,2}\left(y_{w}\right)\right)\right) \\
& -\left(G_{y}+r_{21} x_{w 1,2}\left(y_{w}\right)+r_{22} y_{w}\right. \\
& -r_{23} \sqrt{w\left(y_{w}\right)^{2}-x_{w 1,2}\left(y_{w}\right)^{2}} \\
& \left.-y_{r 1,2}\left(y_{w}\right)\right)=0
\end{aligned}
$$

where $r^{\prime}\left(y_{r}\right)$ is the first derivative of the generative function $r\left(y_{r}\right), r_{i j}$ are the elements of the $R_{2}$ matrix and $G_{x}, G_{y}, G_{z}$ are the coordinates of the wheelset center of mass in the auxiliary system. The (4) are easy to solve numerically with the advantages previously mentioned (in the following $y_{w}^{C}$ will be the generic solution of these equations). For each $y_{w}^{C}$, the values of the unknowns $x_{w}^{C}, x_{r}^{C}, y_{r}^{C}$ and consequently the contact point positions on the wheel and the rail $\mathbf{p}_{w}^{r, C}=p_{w}^{r}\left(x_{w}^{C}, y_{w}^{C}\right)$ and $\mathbf{p}_{r}^{r, C}=p_{r}^{r}\left(x_{r}^{C}, y_{r}^{C}\right)$ can be determined by substitution.

The following physical conditions have also to be respected so that the contact is physically possible:

- the penetration between the wheel and rail surfaces $\left(p_{n}=\mathbf{d}^{r} \cdot \mathbf{n}_{r}^{r}\right.$ ) have to be less or equal to zero, according to the adopted nomenclature;

- multiple solutions have to be rejected;

- the normal curvatures of the wheel and rail surfaces in the longitudinal and lateral direction $\left(k_{1, w}^{C}, k_{1, r}^{C}\right.$, $k_{2, w}^{C}, k_{2, r}^{C}$ ), evaluated in the contact points, have to satisfy the convexity condition in order to make the contact physically possible $\left(k_{1, w}^{C}+k_{1, r}^{C}>0 ; k_{2, w}^{C}+\right.$ $\left.k_{2, r}^{C}>0\right)$. 


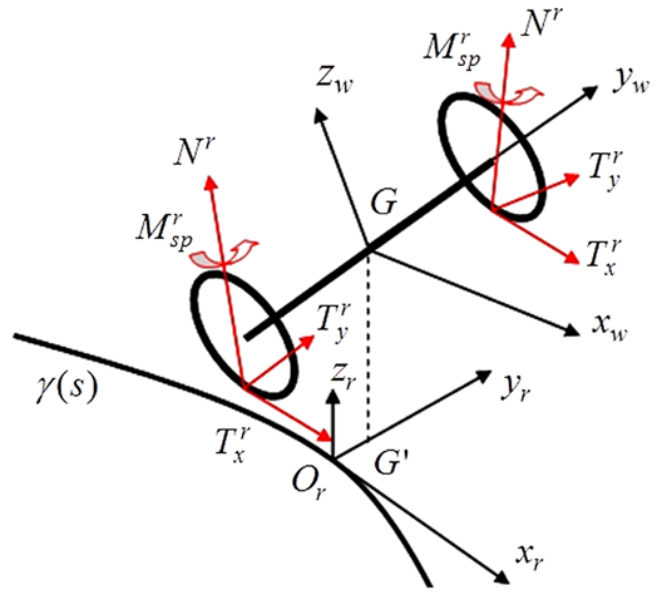

Fig. 5 Nomenclature of the contact forces

For each contact point the global creepages $\xi$ in the contact patch and then the normal $N^{r}$ and tangential contact forces $\mathbf{T}^{r}, M_{s p}^{r}$ (evaluated by means of the Hertz's and the Kalker's global theory respectively) are determined (Fig. 5) [1, 8, 12]:

$$
\begin{aligned}
N^{r}\left(\mathbf{p}_{r}^{r, C}\right)= & {\left[-k_{h}\left|p_{n}\right|^{\gamma}+k_{v}\left|v_{n}\right| \frac{\operatorname{sgn}\left(v_{n}\right)-1}{2}\right] } \\
& \times \frac{\operatorname{sgn}\left(p_{n}\right)-1}{2}
\end{aligned}
$$

where $\gamma$ is equal to $3 / 2, k_{h}$ is a Kalker's stiffness constant depending on the surface geometries and the material properties, $k_{v}$ is a damping contact constant [12].

$T_{x}^{r}\left(\mathbf{p}_{r}^{r, C}\right)=-f_{11} \xi_{x}$

$T_{y}^{r}\left(\mathbf{p}_{r}^{r, C}\right)=-f_{22} \xi_{y}-f_{23} \xi_{s p}$

$M_{s p}^{r}\left(\mathbf{p}_{r}^{r, C}\right)=-f_{23} \xi_{y}-f_{33} \xi_{s p}$

where the value of the $f_{i j}$ coefficients, which are function of the material properties and the ellipse semiaxes, can be found in literature [12]. The global creepages $\boldsymbol{\xi}$ (longitudinal $\xi_{x}$, lateral $\xi_{y}$ and spin creepage $\xi_{s p}$ ) are calculated as follows:

$\xi_{x}=\frac{\mathbf{V} \bullet \dot{\mathbf{i}}_{r}}{\left|\dot{\mathbf{O}}_{w}^{r}\right|}, \quad \xi_{y}=\frac{\mathbf{V} \bullet \mathbf{t}_{r}^{r}\left(\mathbf{P}_{r}^{r}\right)}{\left|\dot{\mathbf{O}}_{w}^{r}\right|}$

$\xi_{s p}=\frac{\boldsymbol{\omega}_{w}^{r} \bullet \mathbf{n}_{r}^{r}\left(\mathbf{P}_{r}^{r}\right)}{\left|\dot{\mathbf{O}}_{w}^{r}\right|}$

where $\mathbf{V}$ is the velocity of contact point rigidly connected to the wheelset, $\dot{\mathbf{O}}_{w}^{r}$ is the wheelset center of mass velocity (taken as the reference velocity for the

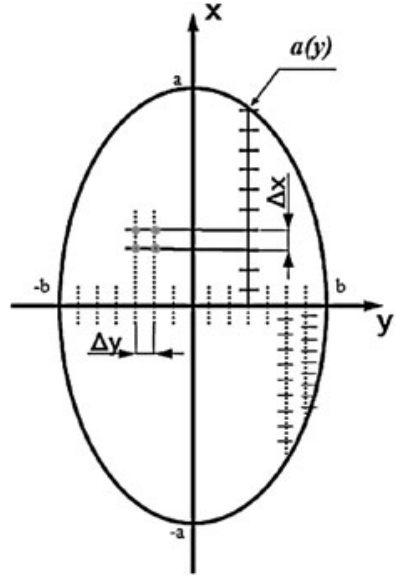

Fig. 6 Contact patch discretization

calculation of the global creepages), $\boldsymbol{\omega}_{w}^{r}$ is the angular velocity of wheelset expressed in auxiliary system, $\mathbf{i}_{r}$ is the unit vector in longitudinal direction of the auxiliary system and $\mathbf{t}_{r}^{r}$ is the tangential unit vector to the rail profile.

\section{The wear evaluation}

\subsection{The local contact model}

The local contact model starts from the global contact variables evaluated by the vehicle model (contact points position $\mathbf{p}_{w}^{r}, \mathbf{p}_{r}^{r}$, contact forces and spin moments $N^{r}, \mathbf{T}^{r}, M_{s p}^{r}$, global creepages $\boldsymbol{\xi}$ and patch semiaxes $a, b)$ and calculates the local contact variables (normal pressures $p_{n}$, tangential stresses $\mathbf{p}_{t}$ and local slip s) within each contact patch. The model is based on an approximate but very efficient version of the Kalker's local theory implemented in his FASTSIM algorithm [12], commonly used in railway multibody simulations. The algorithm works in a local reference system, whose origin is situated in the centre of the elliptical contact patch, with the $x, y$ axis defined in the common tangent plane to the contact surfaces (Fig. 6).

The working hypothesis on which the algorithm is developed is the proportionality between the tangential pressure $\mathbf{p}_{t}$ and the elastic displacements $\mathbf{u}$ in a generic point of the contact patch:

$\mathbf{u}(x, y)=L \mathbf{p}_{t}(x, y) ; \quad L=L(\xi, a, b, G, v)$ 


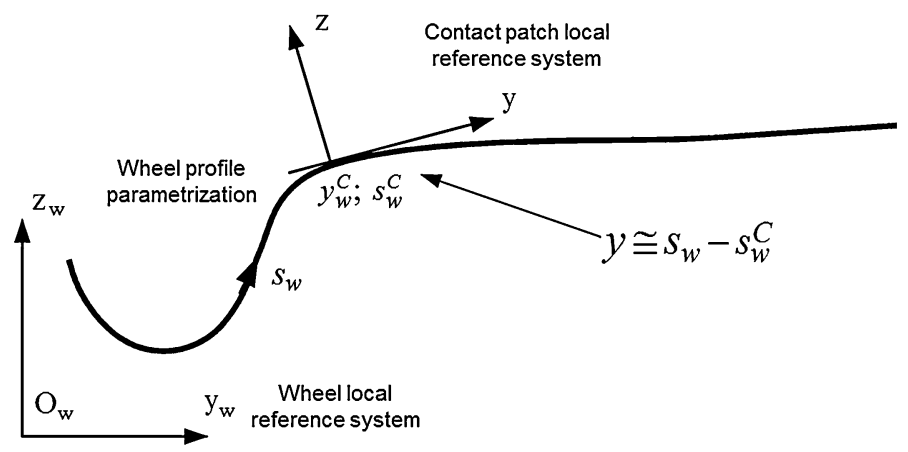

Fig. 7 Wheel profile parametrization

where the flexibility $L$ is a function of the global creepage vector $\xi$, the ellipse semiaxes $a, b$, the combined shear modulus $G$ and the combined Poisson's coefficient $v$ [12].

The calculation of the local variables $p_{n}, \mathbf{p}_{t}$ and $\mathbf{s}$ is iteratively performed in each point of the grid adopted to mesh the contact patch (Fig. 6): the transversal axis of the contact ellipse, with respect to the traveling direction, is divided in $n_{y}-1$ parts with a length of $\Delta y=2 b /\left(n_{y}-1\right)$ by means of $n_{y}$ equidistant nodes. Similarly the longitudinal sections of the patch which are $2 a(y)=2 a \sqrt{1-(y / b)^{2}}$ long are divided in $n_{x}-1$ equal parts of $\Delta x(y)=2 a(y) /\left(n_{x}-1\right)$ length using $n_{x}$ equidistant nodes. This choice leads to a not constant longitudinal resolution which increases in the nearby of the lateral edges of the ellipse, where the length $a(y)$ are shorter. So, the accuracy near the edge is appreciably higher than that obtainable with a constant resolution grid (in this second case more numerical noise and numerical errors would be present). The $n_{x}$ and $n_{y}$ parameters have to be chosen as a compromise between numerical efficiency and precision; the range $25-50$ has proven to work fine.

\subsection{The wear model}

As discussed in the previous paragraphs, the following working hypothesis have been introduced to approach the problem:

- the wear affects only the wheels, while the rails keep their profiles constant during the whole process (a different mean worn rail profile for each statistical analysis class);

- the wear is evaluated according to a law experimentally proven that links the volume of removed material and the frictional work $[2,7]$;
- the output of the wear model is a single mean wheel profile to be used in the next step, which includes the effect of the wear on all the vehicle's wheels;

- dry conditions in the wheel-rail interface.

Despite the working hypotheses and the approximations introduced before and in Sect. 2, the suitability and the extendibility of wear models derived from experimental laboratory tests (like that employed in this work) in predicting the wear evolution in real operative conditions turn out to be quite good (especially taking into account the accuracy level and numerical efficiency required by these applications); for this reason this kind of models is currently very important and widely used in the railway field (see by example [2] and [7]).

As stated previously, the calculation of the wear on the wheel is based on an experimental law according to which the volume of removed material is correlated to the total frictional work. The main output of the wear model is $\delta_{P_{w i}^{j k}(t)}(x, y)$, expressed in $\mathrm{mm}^{3} /\left(\mathrm{mm}^{2} \mathrm{~m}\right)$, a function of the time which describes the specific volume (the volume per unit of area and per unit of traveled distance) of removed material due to the wear in the $i$-th contact patch of the $j$-th wheel in the $k$-th multibody simulation of the statistical analysis of the track. The three indexes just introduced are variable in the following intervals: $1 \leq j \leq N_{W}$ where $N_{W}$ is the number of the vehicle's wheels, $1 \leq i \leq N_{P}$ where $N_{P}$ is the maximum allowed number of the contact points (as will be explained below) and $1 \leq k \leq N_{C}$ with $N_{C}$ equal to the number of the multibody simulations in the statistical description of the real track.

The quantity $\delta_{P_{w i}^{j k}(t)}(x, y)$ has to be evaluated in each point $\left(x_{h}, y_{l}\right)$ of the contact patch grid. To this aim, the local frictional power in these points can be 


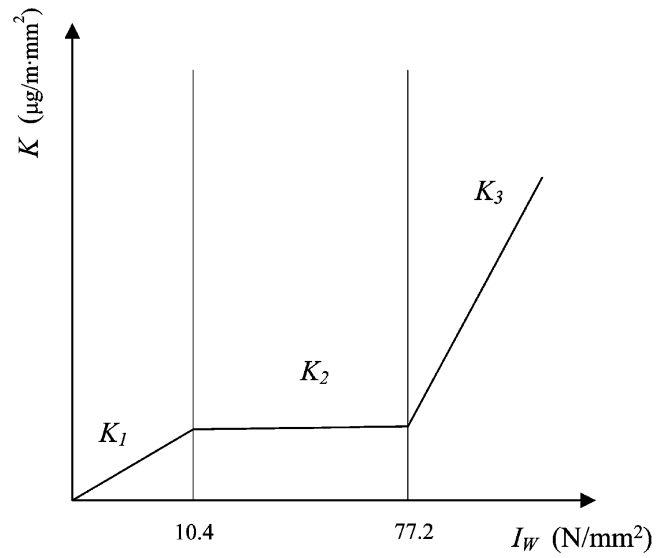

Fig. 8 Trend of the wear rate $K_{W}$

estimated by means of the wear index ( $\mathbf{p}_{t}$ and $\mathbf{s}$ are expressed respectively in $\mathrm{N} / \mathrm{mm}^{2}$ and $\mathrm{m} / \mathrm{s}$ )

$$
I_{W}=\left(\mathbf{p}_{t} \cdot \mathbf{s}\right) / V \quad\left(\mathrm{~N} / \mathrm{mm}^{2}\right),
$$

which is experimentally related to the wear rate $K$ $\left(\mu \mathrm{g} / \mathrm{m} \mathrm{mm}^{2}\right)$ : the wear rate gives a measure of the amount of material removed per meter of traveled distance by the train and per $\mathrm{mm}^{2}$ of surface. The analytic expression for $K\left(I_{W}\right)$ is given by Eq. $(10)[2,7]$ (see Fig. 7 and Fig. 8):

$$
\begin{aligned}
& K_{W}\left(I_{W}\right) \\
& = \begin{cases}5.3 \cdot I_{W} & I_{W}<10.4 \mathrm{~N} / \mathrm{mm}^{2} \\
55.0 & 10.4 \leq I_{W} \leq 77.2 \mathrm{~N} / \mathrm{mm}^{2} \\
61.9 \cdot I_{W}-4723 & I_{W}>77.2 \mathrm{~N} / \mathrm{mm}^{2}\end{cases}
\end{aligned}
$$

where the relation $K_{W}\left(I_{W}\right)$ is valid for the couple of materials R8T steel for the wheel and UIC60900A steel for the rail under dry conditions. It has to be remarked that the wear index defined by Eq. (9) is a local version of the global index $I_{W}^{g}=\left(\mathbf{T}^{r} \cdot \boldsymbol{\xi}\right) / A$ used in [2] where $\mathbf{T}^{r}$ are the tangential forces, $\boldsymbol{\xi}$ the global creepages and $A$ the contact patch area. After the evaluation of the wear rate, the specific volume $\delta_{P_{w i}^{j k}(t)}(x, y)$ can be calculated as follows:

$\delta_{P_{w i}^{j k}(t)}(x, y)=\frac{K\left(I_{W}\right)}{\rho} \quad\left(\frac{\mathrm{mm}^{3}}{\mathrm{mmm}^{2}}\right)$

in which $\rho$ is the material density (expressed in $\left.\mathrm{kg} / \mathrm{m}^{3}\right)$.

\subsection{The profile update}

The profile update is the part of the whole architecture which provides, by means of numerical procedures, the wheel profile for the next step $r_{n}\left(y_{w}\right)$ starting from the profile used at the current step $r_{p}\left(y_{w}\right)$ and exploiting the results of the wear model. It is surely a key point of the procedure since the adopted strategy may appreciably affects the results. The importance of this task is due to a series of distinct issues:

- the wear model, according to the working hypotheses, has to generate as output a single wheel profile, taking into account the data relative to all the vehicle's wheels. A single function of material to be removed has to be obtained from the analysis of all the contact patches;

- due to the discrete approach to the wheel geometry update, the distribution $\delta_{P_{i}^{j k}(t)}(x, y)$ presents a quite considerable numerical noise and needs to be treated to avoid, as stated previously, a non-physical profile with short spatial wavelengths, which may not be handled by the global contact model.

In regard to the first point, the whole model can easily handle different wheel profiles to distinguish the wear evolution of each wheel. Nevertheless, the average of the profile on all the wheels has been adopted to meet the requirements of the research project issued by Trenitalia S.p.A (one single wheel profile as output of the whole wear model), which aims at a wheel profile optimization in future.

The numerical procedures which provide the new profile are described below:

(1) Longitudinal integration:

$$
\begin{gathered}
\frac{1}{2 \pi w\left(y_{w i}^{j k}\right)} \int_{-a(y)}^{a(y)} \delta_{P_{w i}^{j k}}(x, y) d x \\
=\delta_{P_{w i}^{j k}(t)}^{t o t}(y)\left(\frac{\mathrm{mm}^{3}}{\mathrm{mmm}^{2}}\right) ;
\end{gathered}
$$

this operation sums all the wear contributions in the longitudinal direction and spreads them along the circumference of the wheel.

(2) Time integration:

$$
\begin{aligned}
& \int_{T_{i}}^{T_{f}} \delta_{P_{w i}^{j k t}}^{t o t}\left(s_{w}-s_{w i}^{j k, C}(t)\right) V(t) d t \\
& \quad \cong \Delta_{P_{w i}^{j k}}\left(s_{w}\right) \quad(\mathrm{mm})
\end{aligned}
$$




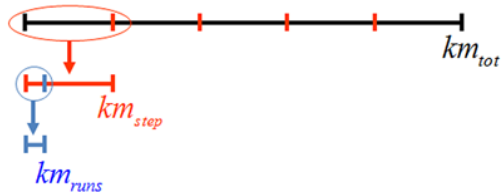

Fig. 9 Discretization of the total mileage

where $y \cong s_{w}-s_{w i}^{j k, C}$ (see Fig. 7 and Fig. 8); $s_{w}$ is the generic curvilinear abscissa of the wheel profile, $s_{w i}^{j k, C}(t)$ is the curvilinear abscissa of the contact point on the wheel at the time $t$ and $V(t)$ is the vehicle speed. The integration performs the sum of all the contributions during the dynamic simulation: the result is the depth of material to be removed due to the considered contact point.

(3) Sum on the contact points and average on the wheels and on the simulations:

$\sum_{k=1}^{N_{C}} p_{k} \frac{1}{N_{W}} \sum_{j=1}^{N_{W}} \sum_{i=1}^{N_{P}} \Delta_{P_{w i}^{j k}}\left(s_{w}\right)=\bar{\Delta}\left(s_{w}\right) ;$

this operation involves the sum on the $N_{P}$ contact points for each wheel, the average on the $N_{W}$ wheels and the weighted average on the $N_{C}$ simulations. As explained in next paragraph, the $p_{k}, 1 \leq k \leq N_{C}$, $\sum_{i=1}^{N_{C}} p_{k}=1$ are the normalized weights related to the tracks of the statistical analysis. The contact patches are usually less than $N_{P}$ and their number can vary during the simulation; hence, since the sum is extended to $N_{P}$, the contribution of the missing points has been automatically set equal to zero.

\section{(4) Scaling of the mileage:}

Since an appreciable evolution of the wheel profile requires thousands of kilometers to manifest itself, the scaling of the distance becomes critically important to get results in a reasonable time.

To this aim a linear relation between wear and traveled distance has been supposed inside the discrete steps $\mathrm{km}_{\text {step }}$ in which the total mileage traveled $\mathrm{km}_{\text {tot }}$ is subdivided. This working hypothesis is based on the idea that the wear rate inside the simulated distance $\left(k m_{\text {runs }}\right)$ remains the same also inside the discrete step $\mathrm{km}_{\text {step }}$, since the considered vehicle always covers the same tracks of the statistical analysis both during the simulated distance $\left(\mathrm{km}_{\text {runs }}\right)$ and during the discrete step $\left(k m_{\text {step }}\right)$. For these reasons the following scaling can be adopted (see Fig. 9):

$\bar{\Delta}\left(s_{w}\right) \frac{k m_{\text {step }}}{k m_{\text {runs }}}=\bar{\Delta}^{s c}\left(s_{w}\right)$.

The amount of removed material $\bar{\Delta}\left(s_{w}\right)$ depends on the overall mileage traveled by the vehicle during the $N_{C}$ simulations of the statistical analysis (that is $k m_{\text {runs }}=L_{C}$, where $L_{C}$ is the length of curved tracks on which the results of the vehicle dynamics are evaluated). After the scaling, the quantity $\bar{\Delta}^{s c}\left(s_{w}\right)$ is related to a spatial step with a length equal to $k m_{\text {step }}$, instead of $\mathrm{km}_{\text {runs }}$. If the numerically simulated tracks are a significant statistical representation of the real track associated to the discrete spatial step, the adopted working hypothesis is reasonable; obviously the proportionality is exploited only within a distance equal to the $\mathrm{km}_{\text {step }}$ and the nonlinearity of the physical problem is preserved.

(5) Smoothing of the amount of removed material:

$\Im\left[\bar{\Delta}^{s c}\left(s_{w}\right)\right]=\bar{\Delta}_{s m}^{s c}\left(s_{w}\right)$.

This procedure aims to realize the filtering of numerical noise and the removal of physically meaningless short spatial wavelengths on the wheel profile. The numerical noise and the short wavelength contributions are treated with a discrete filter: a moving mean with a window width equal to the $1-5 \%$ of the total number of points in which the wheel profile is discretized.

(6) Profile update:

$$
\begin{gathered}
\left(\begin{array}{c}
y_{w}\left(s_{w}\right) \\
r_{p}\left(y_{w}\left(s_{w}\right)\right)
\end{array}\right)-\bar{\Delta}_{s m}^{s}\left(s_{w}\right) \mathbf{n}_{r}^{r} \\
\stackrel{\text { re-parametrization }}{\longrightarrow}\left(\begin{array}{c}
y_{w}^{*}\left(s_{w}\right) \\
r_{n}^{*}\left(y_{w}\left(s_{w}\right)\right)
\end{array}\right) .
\end{gathered}
$$

Finally, the profile for the next step is obtained removing the material in the normal direction from the current profile $r_{p}\left(s_{w}\right)$ (according to the function $\left.\bar{\Delta}_{s m}^{s}\left(s_{w}\right)\right)$ and then performing a new parametrization, to get again a curve parametrized by means of the curvilinear abscissa. 
Table 3 The $N_{C}$ tracks of the statistical approach

\begin{tabular}{|c|c|c|c|c|c|c|}
\hline $\begin{array}{l}R_{\min } \\
(\mathrm{m})\end{array}$ & $\begin{array}{l}R_{\max } \\
(\mathrm{m})\end{array}$ & $\begin{array}{l}\text { Superelevation } \\
h_{\min }-h_{\max } \\
(\mathrm{mm})\end{array}$ & $\begin{array}{l}R_{m} \\
(\mathrm{~m})\end{array}$ & $\begin{array}{l}h \\
(\mathrm{~mm})\end{array}$ & $\begin{array}{l}V \\
(\mathrm{~km} / \mathrm{h})\end{array}$ & $\begin{array}{l}p_{k} \\
\%\end{array}$ \\
\hline \multirow[t]{5}{*}{147.1} & 156.3 & 0 & - & - & - & - \\
\hline & & $10-40$ & - & - & - & - \\
\hline & & $60-80$ & - & - & - & - \\
\hline & & $90-120$ & 150 & 120 & 55 & 0.77 \\
\hline & & $130-160$ & - & - & - & - \\
\hline \multirow[t]{5}{*}{156.3} & 166.7 & 0 & - & - & - & - \\
\hline & & $10-40$ & - & - & - & - \\
\hline & & $60-80$ & - & - & - & - \\
\hline & & $90-120$ & 160 & 110 & 55 & 0.48 \\
\hline & & $130-160$ & 165 & 140 & 55 & 0.56 \\
\hline \multirow[t]{5}{*}{166.7} & 178.6 & 0 & - & - & - & - \\
\hline & & $10-40$ & - & - & - & - \\
\hline & & $60-80$ & - & - & - & - \\
\hline & & $90-120$ & 170 & 110 & 55 & 0.82 \\
\hline & & $130-160$ & 175 & 130 & 55 & 1.55 \\
\hline \multirow[t]{5}{*}{178.6} & 192.3 & 0 & - & - & - & - \\
\hline & & $10-40$ & - & - & - & - \\
\hline & & $60-80$ & - & - & - & - \\
\hline & & $90-120$ & 190 & 100 & 55 & 8.37 \\
\hline & & $130-160$ & 180 & 130 & 55 & 0.45 \\
\hline \multirow[t]{5}{*}{192.3} & 208.3 & 0 & - & - & - & - \\
\hline & & $10-40$ & - & - & - & - \\
\hline & & $60-80$ & - & - & - & - \\
\hline & & $90-120$ & 200 & 90 & 55 & 20.64 \\
\hline & & $130-160$ & 200 & 130 & 60 & 4.00 \\
\hline \multirow[t]{5}{*}{208.3} & 227.3 & 0 & - & - & - & - \\
\hline & & $10-40$ & - & - & - & - \\
\hline & & $60-80$ & 220 & 80 & 55 & 0.70 \\
\hline & & $90-120$ & 220 & 100 & 55 & 3.76 \\
\hline & & $130-160$ & - & - & - & - \\
\hline \multirow[t]{5}{*}{227.3} & 250.0 & 0 & - & - & - & - \\
\hline & & $10-40$ & - & - & - & - \\
\hline & & $60-80$ & 240 & 80 & 55 & 7.26 \\
\hline & & $90-120$ & 240 & 110 & 60 & 5.28 \\
\hline & & $130-160$ & - & - & - & - \\
\hline \multirow[t]{5}{*}{250.0} & 312.5 & 0 & - & - & - & - \\
\hline & & $10-40$ & - & - & - & - \\
\hline & & $60-80$ & 270 & 70 & 55 & 3.91 \\
\hline & & $90-120$ & 270 & 90 & 60 & 5.29 \\
\hline & & $130-160$ & - & - & - & - \\
\hline
\end{tabular}


Table 3 (Continued)

\begin{tabular}{|c|c|c|c|c|c|c|}
\hline $\begin{array}{l}R_{\text {min }} \\
(\mathrm{m})\end{array}$ & $\begin{array}{l}R_{\max } \\
(\mathrm{m})\end{array}$ & $\begin{array}{l}\text { Superelevation } \\
h_{\min }-h_{\max } \\
(\mathrm{mm})\end{array}$ & $\begin{array}{l}R_{m} \\
(\mathrm{~m})\end{array}$ & $\begin{array}{l}h \\
(\mathrm{~mm})\end{array}$ & $\begin{array}{l}V \\
(\mathrm{~km} / \mathrm{h})\end{array}$ & $\begin{array}{l}p_{k} \\
\%\end{array}$ \\
\hline \multirow[t]{5}{*}{312.5} & 416.7 & 0 & - & - & - & - \\
\hline & & $10-40$ & - & - & - & - \\
\hline & & $60-80$ & 370 & 60 & 55 & 2.26 \\
\hline & & $90-120$ & 345 & 100 & 70 & 1.63 \\
\hline & & $130-160$ & - & - & - & - \\
\hline 416.7 & $\infty$ & 0 & $\infty$ & 0 & 70 & 32.27 \\
\hline
\end{tabular}

\section{Statistical approach to the track and model validation}

\subsection{The Aosta-Pre Saint Didier line}

The statistical approach to the track has been chosen to reduce and rationalize the total simulation work, avoiding excessively long simulations on the real track (see Table 3). The idea is to substitute the simulation on the whole track with an equivalent set of simulations on short curved tracks. More precisely, the steps performed to get the statistical representation were the following:

- a set of radius curve intervals characterized by a minimum $R_{\min }$ and a maximum $R_{\max }$ were identified analyzing the database provided by RFI;

- each of these intervals was furthermore divided in superelevation subclasses, each of them with its own $h_{\min }$ and $h_{\max }$;

- for each subclasses a representative radius $R_{m}$ was calculated as a weighted average on all the curve radii included in that subclasses, using the length of curve as a weighting factor;

- the correspondent representative superelevation $h$ was chosen as the most frequent superelevation among the values found in that class;

- for each subclasses a speed value $V$ was chosen as the minimum value between the max speed allowable equal to $V_{\max }=70 \mathrm{~km} / \mathrm{h}$ (depending on the radius, the superelevation and vehicle characteristics) and the speed $\tilde{V}$ calculated imposing a noncompensated acceleration of $a_{n c}^{l i m}=0.6 \mathrm{~m} / \mathrm{s}^{2}$

$$
\frac{\tilde{V}^{2}}{R_{c}}-\frac{H}{s} g=a_{n c}^{l i m} ; \quad V=\min \left(\tilde{V}, V_{\max }\right)
$$

- a weighting factor $p_{k}$ was introduced for each subclass to take into account the frequency of a certain matching radius-superelevation in the track and to diversify the wear contributions of the different curves;

- the transition lengths of the real track are incorporated in the constant curvature sections next to them (the inner transition is included in the previous constant curvature section while the outer transition is included in the next one), hence the wear is numerically evaluated on curves and straight tracks only.

The statistical analysis of the Aosta-Pre Saint Didier railway line is based on the data and on the knowhow provided by Trenitalia and Rete Ferroviaria Italiana during this research activity (concerning both the track characteristics and the assumptions behind the statistical approach) [23]. From an operative point of view, a compromise is needed in terms of accuracy and numerical efficiency; an excessively rough statistical analysis (few classes of curves) would provide inaccurate results and short computation times while an excessively detailed one (too many classes of curves) exactly the contrary.

The statistical approach to the Aosta-Pre Saint Didier railway line has provided the classification shown in Table 3, made up of $N_{C}$ different classes (17 curves and the straight track). For each one of the $N_{C}$ class of curves a different constant average worn rail profile provided by RFI, obviously characterized by a different wear between inner and outer side, has been considered (in Fig. 10 are represented the outer rail profiles); particularly the rail profiles have more severe wear if the curve radius decreases because of the worse contact conditions characterizing the wheel-rail pairs.

The choice of using constant average worn rail profiles (one for each class of curves) is a working hypoth- 


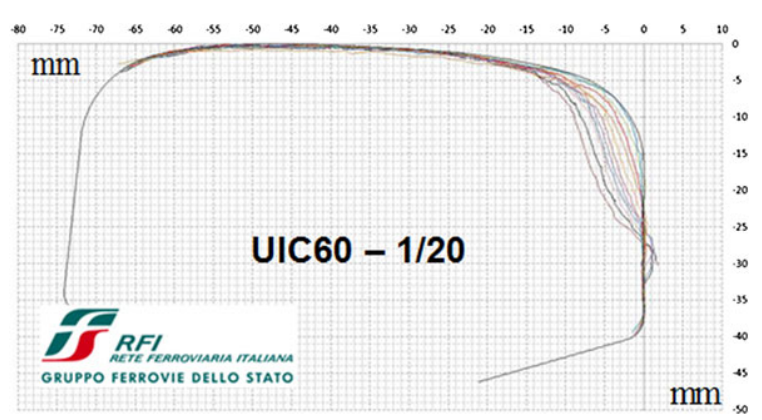

Fig. 10 Average worn outer rail profiles

esis with the aim of getting an accurate wear estimations in real operative conditions: in fact rail profiles characterized by different wear conditions (absence of wear, middle wear, severe wear etc.) may be present in a real railway track. In particular constant new rail profiles could produce an overestimation of the wheel wear due to the initial not conformal contact between wheel and rail (especially in Italy where the coupling ORE S1002-UIC60 canted at $1 / 20$ is used) while, on the contrary, constant totally worn rail profiles could produce an underestimation of the wear due to the initial more conformal contact. Since using a rail profile variable along the track would have been quite heavy in terms of computational load and hardly consistent with a statistical analysis, the authors choice also in this case to follow a compromise based on a statistical approach; according to the Trenitalia requirements and thanks to the data and measurements provided by Rete Ferroviaria Italiana, a constant average (in statis- tical sense) worn rail profile for each class of curves has been considered.

\subsection{Wheel profile reference dimensions}

According to [6], the wear progress in a wheel profile can be easily represented through three reference dimensions, avoiding a complete detection of the shape: the flange thickness FT, the flange height $\mathrm{FH}$ and the QR dimension (Fig. 11). These quantities are defined in the following manner:

- the point $\mathrm{P} 0$ on the profile is $70 \mathrm{~mm}$ distant from the internal side of the wheel;

- the point $\mathrm{P} 1$ is $2 \mathrm{~mm}$ above the lowest point $\mathrm{V}$ of the flange on the wheel profile;

- the point $\mathrm{P} 2$ is $10 \mathrm{~mm}$ below $\mathrm{P} 0$ on the profile;

- the flange thickness FT is defined as the distance between P2 and the internal vertical side of the wheel; $\mathrm{QR}$ is the horizontal distance between $\mathrm{P} 1$ and $\mathrm{P} 0$; the flange height $\mathrm{FH}$ is the vertical distance between $\mathrm{P} 0$ and $\mathrm{V}$.

Because of the way the quotas are defined, they are positive and do not depend on the wheel rolling radius. The values of these parameters are measured periodically in order to decide whether the profile has to be re-turned or not (if it is still possible), considering the maximum or minimum values suggested by the regulation in forces [6]. The check of the reference quotas aims to guarantee mainly the safety against the hunting and the derailment, as well as an acceptable running behavior. In regard to their physical meaning, both the

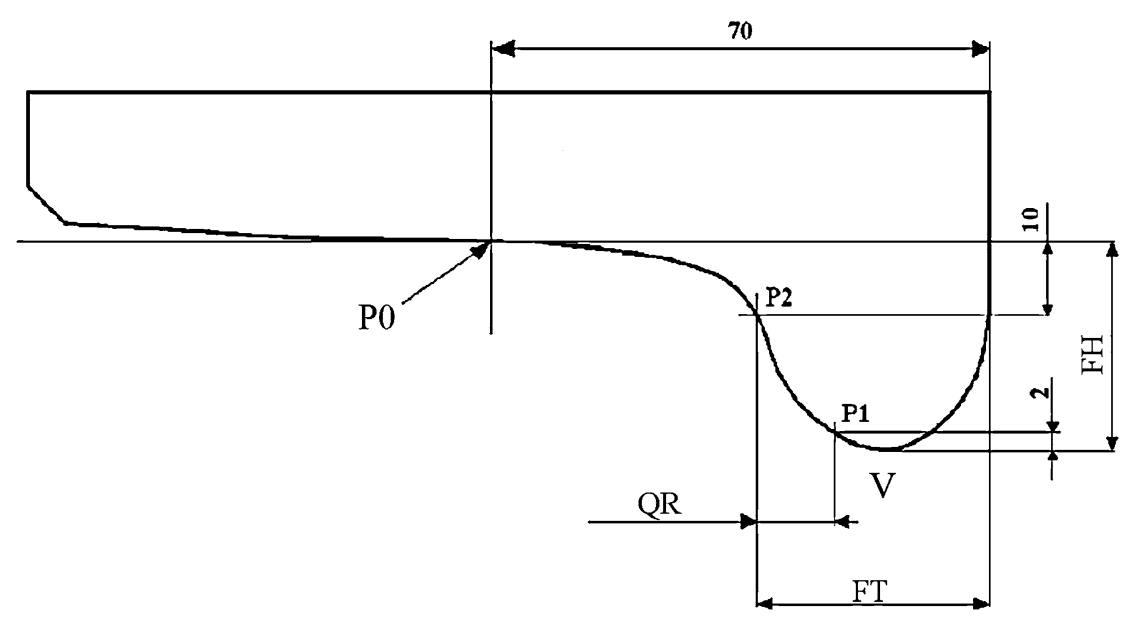

Fig. 11 Reference dimensions 


\begin{tabular}{|c|c|c|c|c|c|c|c|c|c|c|c|c|c|c|c|c|c|}
\hline \multirow[b]{2}{*}{$\mathrm{km}$} & \multirow{2}{*}{$\begin{array}{c}\text { flange } \\
\text { dimensions }\end{array}$} & $1 \mathrm{r}$ & 11 & $2 \mathrm{r}$ & 21 & $3 r$ & 31 & $4 \mathrm{r}$ & 41 & $5 \mathrm{r}$ & 51 & $6 r$ & 61 & $7 \mathrm{r}$ & 71 & $8 \mathrm{r}$ & 81 \\
\hline & & \multicolumn{2}{|c|}{$\begin{array}{c}\text { wheel diameter } \\
816 \mathrm{~mm} \\
\end{array}$} & \multicolumn{2}{|c|}{$\begin{array}{c}\text { wheel diameter } \\
815 \mathrm{~mm}\end{array}$} & \multicolumn{2}{|c|}{$\begin{array}{c}\text { wheel diameter } \\
824 \mathrm{~mm}\end{array}$} & \multicolumn{2}{|c|}{$\begin{array}{c}\text { wheel diameter } \\
823 \mathrm{~mm}\end{array}$} & \multicolumn{2}{|c|}{$\begin{array}{c}\text { wheel diameter } \\
823 \mathrm{~mm}\end{array}$} & \multicolumn{2}{|c|}{$\begin{array}{c}\text { wheel diameter } \\
823 \mathrm{~mm}\end{array}$} & \multicolumn{2}{|c|}{$\begin{array}{c}\text { wheel diameter } \\
819 \mathrm{~mm}\end{array}$} & \multicolumn{2}{|c|}{$\begin{array}{c}\text { wheel diameter } \\
820 \mathrm{~mm}\end{array}$} \\
\hline \multirow{3}{*}{ U } & FT & 30.953 & 30.944 & 30.983 & 30.784 & 31.099 & 30.957 & 30.938 & 31.076 & 30.401 & 30.367 & 30.830 & 30.987 & 30.437 & 30.717 & 30.852 & 30.933 \\
\hline & FH & 27.970 & 27.894 & 28.141 & 28.043 & 27.969 & 28.187 & 28.030 & 28.271 & 28.245 & 27.918 & 28.141 & 27.982 & 28.013 & 27.937 & 28.333 & 27.883 \\
\hline & QR & 10.208 & 10.140 & 10.424 & 10.457 & 10.220 & 10.306 & 10.279 & 10.833 & 10.332 & 10.445 & 10.364 & 10.219 & 10.421 & 10.500 & 10.338 & 10.396 \\
\hline \multirow{3}{*}{1426} & & 29.855 & 28.977 & 30.283 & 29.317 & 30.118 & 29.383 & 30.152 & 29.450 & 29.796 & 29.799 & 30.288 & 29.483 & 29.802 & 29.085 & 30.267 & 29.316 \\
\hline & $\mathrm{H}$ & 28.010 & 27.923 & 28.104 & 28.108 & 28.000 & 28.249 & 28.095 & 28.278 & 28.248 & 28.284 & 28.247 & 28.030 & 28.997 & 28.003 & 30.383 & 27.919 \\
\hline & $\mathrm{QR}$ & 9.297 & 8.226 & 9.822 & 8.956 & 9.344 & 8.749 & 9.511 & 9.072 & 9.635 & 9.767 & 9.773 & 8.763 & 9.593 & 8.883 & 9.675 & 8.762 \\
\hline \multirow{3}{*}{2001} & FT & 29.056 & 28.498 & 29.722 & 28.878 & 29.441 & 28.667 & 29.629 & 28.717 & 29.153 & 28.101 & 29.739 & 28.841 & 29.066 & 28.447 & 29.625 & 28.777 \\
\hline & $\mathrm{FH}$ & 27.990 & 27.880 & 28.161 & $28,0,80$ & 29.998 & 28.248 & 28.128 & 28.283 & 28.290 & 27.994 & 28.273 & 28.022 & 28.027 & 28.014 & 28.362 & 27.957 \\
\hline & $Q R$ & 8.404 & 7.558 & 9.233 & 8.637 & 8.702 & 7.950 & 8.873 & 8.436 & 9.144 & 8.141 & 9.236 & 8.086 & 9.038 & 8.152 & 9.248 & 8.373 \\
\hline \multirow{3}{*}{2575} & FT & 28.259 & 27.096 & 29.333 & 28.045 & 28.972 & 28.385 & 29.029 & 28.124 & 29.053 & 27.600 & 29.095 & 28.505 & 28.553 & 27.866 & 29.205 & 28.473 \\
\hline & $\mathrm{FH}$ & 28.009 & 27.089 & 28.173 & 28.020 & 28.063 & 28.243 & 28.090 & 28.241 & 28.285 & 27.963 & 28.244 & 28.085 & 28.030 & 28.018 & 28.352 & 27.968 \\
\hline & QR & 7.198 & 7.024 & 8.853 & 8.163 & 8.123 & 7.598 & 8.438 & 7.791 & 8.868 & 7.395 & 8.559 & 7.840 & 8.372 & 7.340 & 8.777 & 7.900 \\
\hline
\end{tabular}

Fig. 12 Experimental data of the ALn 501 Minuetto MD061

Table 4 Values of $k m_{\text {tot }}, k m_{\text {step }}$ and $k m_{\text {runs }}$

\begin{tabular}{lll}
\hline $\begin{array}{l}k m_{\text {tot }} \\
(\mathrm{km})\end{array}$ & $\begin{array}{l}k m_{\text {step }} \\
(\mathrm{km})\end{array}$ & $\begin{array}{l}k m_{\text {runs }} \\
(\mathrm{km})\end{array}$ \\
\hline 3500 & 350 & 0.4 \\
\hline
\end{tabular}

flange thickness FT and the flange height FH describe the size of the flange, while the flange height is also a measure of the wear on the wheel tread. The QR dimension gives information about the flange conicity.

\subsection{Treatment of the experimental data}

The experimental data provided by Trenitalia and RFI are related only to the wheel wear and consist in the wear control parameters measured as a function of the total distance traveled by the considered vehicle $A l n$ 501 Міпиеtto; the quantities are referred to a vehicle traveling time of about two months. Particularly, the data have been measured on three different vehicles operating on the same track (conventionally called MD061, MD068, MD082) and the reference quotas values have been measured for all the vehicle wheels (see Fig. 12). The materials of wheels and rails are respectively R8T steel and UIC60900A steel according to [2]. In the numerical simulations, the distance of $3500 \mathrm{~km}\left(\mathrm{~km}_{\text {tot }}\right)$ has been divided in $N_{\text {step }}=10 \mathrm{steps}$, with a resulting $k m_{\text {step }}$ equal to $350 \mathrm{~km}$; in the standard case $k m_{\text {runs }}$ is equal to $400 \mathrm{~m}$ (Table 4).

The data have been pre-processed in order to obtain a single wheel profile to compare with the simu- lated one and to reduce the measurement errors (see Table 5). In particular:

- initially the arithmetic mean on all the sixteen vehicle wheels has been evaluated; the mean is necessary to obtain a single wheel profile and, at the same time, to reduce the measurement errors affecting the experimental data;

- then a scaling of the quota values has been carried out in order to delete the offset on the initial value of the considered quantities: this procedure imposes that all the wear control parameters start from their nominal values (the standard values for the ORE $S$ 1002 profile have been used) in order to remove the initial differences among the vehicles due to measurement errors;

- the arithmetic mean on the three vehicle MD061, MD068, MD082 has not been carried out, in order to maintain a dispersion range for the experimental data.

\subsection{Progress of the reference dimensions and of the wheel profile}

This section presents the first results of the validation, showing the comparison between the numerically evaluated progresses of the three dimensions (FT, FH and $\mathrm{QR}$ ) and the experimental data.

The progress of the FT dimension is shown in Fig. 13; the decrease of the quota is almost linear with the traveled mileage except in the first phases, where the profiles of wheel and rail are not conformal enough. The FH curve progress is presented in- 
Table 5 Averaging and scaling of experimental data

\begin{tabular}{|c|c|c|c|c|c|c|c|}
\hline \multirow[t]{2}{*}{ Vehicle } & \multirow[t]{2}{*}{$\mathrm{km}$} & \multicolumn{2}{|l|}{$\begin{array}{l}\text { QR } \\
(\mathrm{mm})\end{array}$} & \multicolumn{2}{|l|}{$\begin{array}{l}\mathrm{FH} \\
(\mathrm{mm})\end{array}$} & \multicolumn{2}{|l|}{$\begin{array}{l}\text { FT } \\
(\mathrm{mm})\end{array}$} \\
\hline & & Mean & St. Dev. & Mean & St. Dev. & Mean & St. Dev. \\
\hline \multirow[t]{4}{*}{ MD061 } & 0 & 10.8 & 0.16 & 28.0 & 0.14 & 32.5 & 0.23 \\
\hline & 1426 & 9.8 & 0.48 & 28.2 & 0.61 & 31.5 & 0.43 \\
\hline & 2001 & 9.1 & 0.52 & 28.1 & 0.51 & 30.8 & 0.50 \\
\hline & 2575 & 8.6 & 0.60 & 28.0 & 0.28 & 30.2 & 0.63 \\
\hline \multirow[t]{4}{*}{ MD068 } & 0 & 10.8 & 0.24 & 28.0 & 0.25 & 32.5 & 0.20 \\
\hline & 1050 & 10.0 & 0.65 & 28.0 & 0.23 & 31.8 & 0.49 \\
\hline & 2253 & 8.5 & 0.73 & 28.0 & 0.23 & 30.2 & 0.64 \\
\hline & 2576 & 8.4 & 0.64 & 28.0 & 0.22 & 32.5 & 0.65 \\
\hline \multirow[t]{5}{*}{ MD082 } & 0 & 10.8 & 0.19 & 28.0 & 0.14 & 32.5 & 0.15 \\
\hline & 852 & 10.6 & 0.25 & 28.0 & 0.14 & 32.3 & 0.26 \\
\hline & 1800 & 9.6 & 0.44 & 28.0 & 0.13 & 31.3 & 0.44 \\
\hline & 2802 & 8.7 & 0.58 & 28.8 & 0.18 & 30.3 & 0.56 \\
\hline & 3537 & 8.3 & 0.51 & 28.1 & 0.13 & 30.0 & 0.50 \\
\hline
\end{tabular}

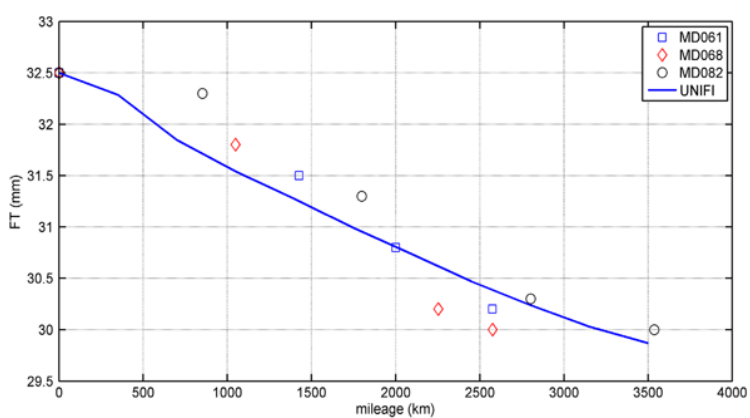

Fig. 13 FT progress

stead in Fig. 14, which shows that, due to the presence of many sharp curves in the track and to the low traveled mileage, the wear is localized mainly on the flange rather than on the tread; thus the flange height remains nearly constant. The comparison between the real and simulated QR is finally shown in Fig. 15: the dimension decreases almost linearly too, leading to an augmentation of the conicity on the flange. As a conclusion, the comparisons show that the results of the wear model are quite consistent with the experimental data, both for the flange dimensions (FT, FH) and the $\mathrm{QR}$; therefore the validation of the model can be considered satisfactory.

The numerical evolution of the wheel profile is presented in Fig. 16. Due to the low covered mileage and

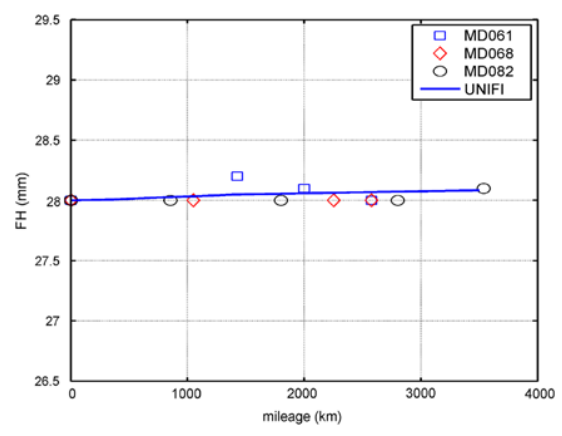

Fig. 14 FH progress

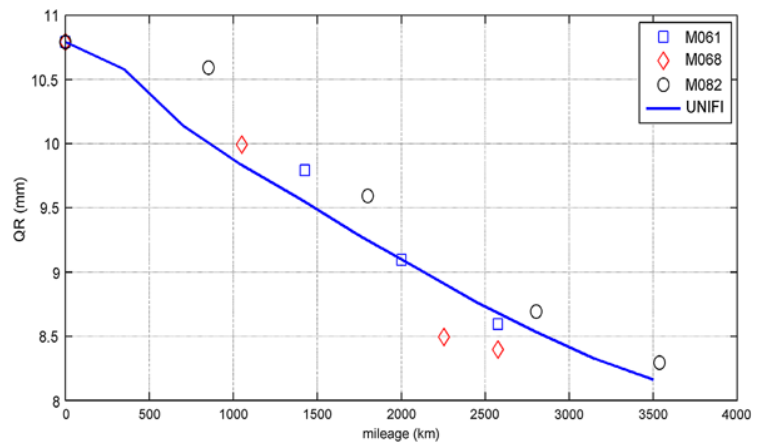

Fig. 15 QR progress

to the sharpness of the track, the wear is mainly localized on the flange rather than on the tread, where it is 


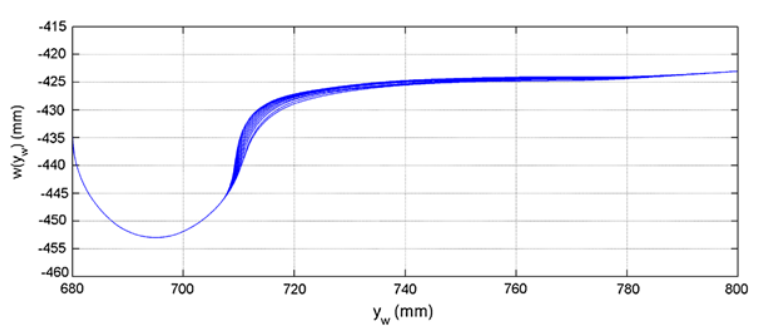

Fig. 16 Evolution of the wheel profile

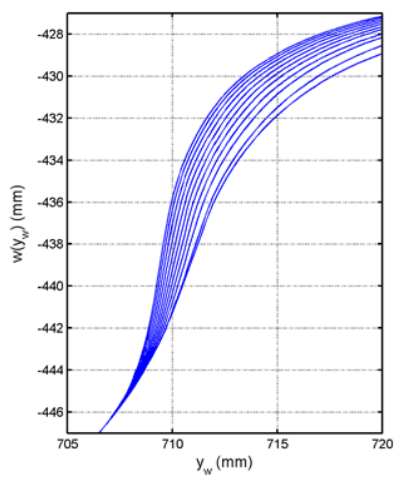

Fig. 17 Evolution in the flange zone

quite low and involves a slight reduction of the rolling radius.

Observing the flange zone, the wear rate is higher during the first steps because of the non-conformal contact due to the coupling between the ORE S1002 wheel profile and the UIC60 rail with an inclination of 1:20 rad; then it decreases becoming more regular and constant in the last phases, when the contact is more and more conformal (Fig. 17).

\section{Conclusions}

In this work the Authors have presented a complete model for the wheel wear prediction in railway applications. The whole model is made up of two mutually interactive parts. The first one evaluates the vehicle dynamics and comprises both the multibody model of the vehicle implemented in Simpack Rail and a global wheel-rail contact model (developed by the Authors in previous works) for the calculation of the contact points and of the contact forces. The second one is the wear model which, starting from the outputs of the multibody simulations, evaluates the amount of material to be removed due to wear. The interaction between the two parts is not a continuous time process but occurs at discrete steps; consequently the evolution of the wheel geometry is described through several intermediate profiles.

The entire model has been validated by exploiting the experimental data relative to a particularly critical scenery in terms of wear in the Italian railways: the ALSTOM Aln 501 "Minuetto" circulating on the Aosta-Pre Saint Didier railway line. A statistical approach to describe the track has been used to reduce the total computational effort. The arising model reproduces properly the evolution of all the three characteristic dimensions of the wheel profile which describe the wear progress. The resultant wheel profile evolution highlights that, in this particular application, the wear is severe and strongly localized on the flange of wheel because of both the sharpness of the track and the low covered mileage considered, leading to frequent maintenance interventions.

Future developments will consist first of all in the study of a model for the simultaneous evaluation of wheel and rail wear (usually evolving on different time scales); at the same time, the new wear model will have to be able to estimate the wear evolution independently on all the vehicle wheels and to take into account the effect of acceleration and braking phases. Moreover, since the employment of statistical approaches for the wear evaluation is an important research topic especially on very complex railway lines with the aim of reducing the computational load and increasing the model accuracy, the authors are currently investigating the sensibility of the results in terms of wear prediction and their dependence on the work hypotheses behind the statistical analysis of the considered railway line.

Acknowledgements Authors would like to thank Engg. R. Cheli and G. Grande of Trenitalia S.p.A for providing and giving the permission to edit the data relative both to the vehicle ALn 501 Minuetto and to the wheel wear evolution; a special thanks also goes to the Engg. R. Mele and M. Finocchi of Rete Ferroviaria Italiana for the data relative to the Aosta-Pre Saint Didier line.

\section{References}

1. Bozzone M, Pennistri E, Salvini P (2010) A lookup tablebased method for wheel-rail contact analysis. Journal of Multibody Dynamics 225:127-138

2. Braghin F, Lewis R, Dwyer-Joyce RS, Bruni S (2006) A mathematical model to predict railway wheel profile evolution due to wear. Wear 261:1253-1264 
3. Carbone G, Bottiglione F (2011) Contact mechanics of rough surfaces: a comparison between theories. Meccanica 46(3):557-565

4. Cheli F, Pennestrì E (2006) Cinematica e dinamica dei sistemi multibody. CEA, Milano, Italy

5. Dukkipati RV, Amyot JR (1988) Computer aided simulation in railway dynamics. Dekker, New York

6. EN 15313 (2011) Railway applications. In service wheelset operation requirements. In service and off-vehicle wheelset maintenance

7. Enblom R, Berg M (2005) Simulation of railway wheel profile development due to wear: influence of disk braking and contact environment. Wear 258:1055-1063

8. Esveld C (2001) Modern railway track. Delft University of Technology, Delft, Netherlands

9. Falomi S, Malvezzi M, Meli E, Rindi A (2009) Determination of wheel-rail contact points: comparison between classical and neural network based procedures. Meccanica 44(6):661-686

10. Iwnicki S (1999) The Manchester benchmarks for rail vehicle simulators. Swets and Zeitlinger, Lisse, Netherlands

11. Jendel T, Berg M (2002) Prediction of wheel profile wear. Vehicle System Dynamics 37:502-513

12. Kalker JJ (1990) Three-dimensional elastic bodies in rolling contact. Kluwer, Dordrecht, Netherlands

13. Krause H, Poll G (1984) Verschleiss bei gleitender und waelzender Relativbewegung. Tribologie und Schmierungstechnik 31(4):209-214

14. Malvezzi M, Meli E, Auciello J, Falomi S (2009) Dynamic simulation of railway vehicles: wheel-rail contact analysis. Vehicle System Dynamics 47(7):867-899
15. Meli E, Falomi S, Malvezzi M, Rindi A (2008) Determination of wheel-rail contact points with semianalytic methods. Multibody System Dynamics 20(4):327-358

16. Meli E, Falomi S, Malvezzi M, Rinchi M (2009) Multibody modelling of railway vehicles: innovative algorithms for the detection of wheel-rail contact points. In: Proceedings of multibody dynamics 2009 (ECCOMAS), Varsavia, Polonia

17. Pearce TG, Sherratt ND (1991) Prediction of wheel profile wear. Wear 144:343-351

18. Pombo J, Ambrosio J (2010) A study on wear evaluation of railway wheels based on multibody dynamics and wear computation. Multibody System Dynamics 24:347-366

19. Shabana AA, Sany JR (2001) An augmented formulation for mechanical systems with non-generalized coordinates: application to rigid body contact problems. Nonlinear Dynamics 24:183-204

20. Shabana AA, Zaazaa KE, Escalona JL, Sany JL (2004) Development of elastic force model for wheel/rail contact problems. Journal of Sound and Vibration 269:295-325

21. Specht W (1985) Beitrag zur rechnerischen Bestimmung des Rad- und schienenverschleisses durch Gueterwagen. Diss. RWTH, Aachen, Germany

22. Telliskivi T, Olofsson U (2004) Wheel-rail wear simulation. Wear 257:1145-1153

23. Toni P (2010) Ottimizzazione dei profili delle ruote su binario con posa 1/20. Technical report of Trenitalia S.p.A, Florence, Italy

24. Zobory I (1997) Prediction of wheel/rail profile wear. Vehicle System Dynamics 28:221-259 